\title{
Pullulan as a stabilizer agent of polymeric nanocapsules for drug delivery
}

\author{
Janaíne Micheli Chassot ${ }^{1}$, Luana Mota Ferreira ${ }^{1}$, Felipe Pereira Gomes ${ }^{1}$, Cristiane de Bona da \\ Silva ${ }^{1}$, Leandro Tasso ${ }^{2}$, Letícia Cruz ${ }^{1, *}$
}

${ }^{1}$ Department of Industrial Pharmacy, Federal University of Santa Maria, Santa Maria, RS, Brazil, ${ }^{2}$ Institute of Biotechnology, University of Caxias do Sul, Caxias do Sul, RS, Brazil

\begin{abstract}
Polymeric stabilizers have received attention in the preparation of nanostructured systems due to their ability to enhance formulation stability. Considering this, the objective of this work was to prepare poly( $\varepsilon$-caprolactone) nanocapsules using the pullulan as a polymeric stabilizer. The nanocapsules were prepared using the interfacial deposition method of preformed polymers and they were characterized in terms of $\mathrm{pH}$, average diameter, polydispersity index, zeta potential, beclomethasone dipropionate content, encapsulation efficiency, photostability and drug release profiles. The formulations showed physicochemical characteristics consistent with nanocarriers for drug delivery such as: average diameter lower than $270 \mathrm{~nm}$, polydispersity indexes lower than 0.2 , negative zeta potential (-22.7 to $-26.3 \mathrm{mV}$ ) and encapsulation efficiencies close to $100 \%$. In addition, the nanocapsules were able to delay the beclomethasone dipropionate photodegradation under UVC radiation and by the dialysis bag diffusion technique, the nanocapsules were able to prolong the drug release. Thus, pullulan could be considered an interesting excipient to formulate polymeric nanocapsules.
\end{abstract}

Uniterms: Pullulan. Nanocapsules/diffusion technique. Pullulan/polymeric stabilizer. Biocompatible polymers. Beclomethasone dipropionate/nanocapsules.

\section{INTRODUCTION}

Nanocapsules are colloidal drug delivery systems characterized by a liquid core surrounded by a polymeric shell (Mora-Huertas, Fessi, Elaissari, 2010). The core is usually composed of liquid lipids but may also present a hydrophilic nature. In such nanostructures the drug is confined in the core and/or absorbed in the polymeric wall (Schaffazick et al., 2003; Kaur et al., 2014).

The nanocapsules preparation requires some raw materials including polymer, oil and a combination of surfactant/cosurfactant. Biodegradable polyesters such as poly( $\varepsilon$-caprolactone), poly(lactide) and poly(lactideco-glycolide) are commonly used (Mora-Huertas, Fessi, Elaissari, 2010). Regarding the core composition, a variety of synthetic and vegetable oils are reported; however, medium chain triglycerides are the most employed ones due to their low toxicity and high capacity to solubilize

\footnotetext{
*Correspondence: L. Cruz. Departamento de Farmácia Industrial. Universidade Federal de Santa Maria. Avenida Roraima, 1000 - 97105-900 - Santa Maria - RS, Brasil. Phone: +55 5532209373 / Fax: +55 55 32208149. E-mail: leticiacruz@smail.ufsm.br
}

a wide range of lipophilic drugs (Preetz et al., 2008). Oil as well as W/O cosurfactants (common sorbitan esters and phospholipids) are also core constituents. The main surfactant, in its turn, acts on the particle surface and plays a major role as a nanocapsule stabilizer agent, being poloxamer 188 and polysorbate 80 more commonly employed (Mora-Huertas, Fessi, Elaissari, 2010). However, such surfactants are known to present some incompatibilities with preservatives and other raw materials (Allen, 2004). As an alternative, polymeric emulsifiers have gained much attention in the preparation of dispersed systems due to their capacity to enhance formulation stability (Bobin, Michel, Martini, 1999).

Pullulan (figure 1) is an extracellular polysaccharide elaborated by the Aureobasidium pullulans fungus. This water-soluble biopolymer presents a linear structure composed of repeating maltotriose units connected by $\alpha-1,6$-glucosidic bonds (Singh, Saini, Kennedy, 2008). Because of its non-toxic, non-carcinogenic and nonimmunogenic properties, the pullulan is being studied for pharmaceutical and biomedical applications (Choudhry et al., 2012). The pullulan efficacy as an emulsifier was 
demonstrated in the emulsification of turmeric oleoresin (Kshiragar et al., 2007); however, no report on the nanoparticles preparation using pullulan as a stabilizer agent has been found. On the other hand, hydrophobically modified pullulan derivatives were employed to prepare nanostructured systems (Hassani, Hendra, Bouchemal, 2012; Park et al., 2012).

In this way, this work aimed to prepare polymeric nanocapsules using pullulan as a stabilizer replacing polysorbate 80 , a traditional surfactant. Besides this change, beclomethasone dipropionate was selected to be incorporated in nanocapsules as a drug model due to its therapeutic potential, and because it is a corticosteroid drug widely used as anti-inflammatory agent in the topical treatment of rhinitis and asthma (Brown, George, 1972). The developed formulation was characterized in terms of $\mathrm{pH}$, particle size and polydispersity index, zeta potential, drug content, encapsulation efficiency, photostability and in vitro drug release.

\section{MATERIAL AND METHODS}

\section{Material}

Beclomethasone dipropionate (BD) was obtained from Henrifarma (São Paulo, Brazil). Poly( $\varepsilon$-caprolactone) (PCL) was supplied by Sigma Aldrich (São Paulo, Brazil), sorbitan monooleate (Span $80^{\circledR}$ ) was purchased from Delaware (Porto Alegre, Brazil) and pullulan was generously gifted by Corn products (São Paulo, Brazil). Medium chain triglycerides (MCT) were obtained from Brasquim (Porto Alegre, Brazil). HPLC-grade methanol was supplied by Tedia (Rio de Janeiro, Brazil). All other solvents and reagents were of analytical grade and used as received.

\section{Analytical procedures}

The experiments were performed on a LC-10A HPLC system (Shimadzu, Japan) equipped with a LC20AT pump, a UV-VIS SPD-M20A detector, a CBM-20A system controller and a Rheodyne valve sample manual injector with $50 \mu \mathrm{L}$ loop. The separation was performed at room temperature using a $\mathrm{RP} \mathrm{C}_{18}$ Phenomenex column $(250 \mathrm{~mm} \times 4.60 \mathrm{~mm}, 5 \mu \mathrm{m} ; 110 \AA)$ coupled to $\mathrm{C}_{18}$ guard column. The isocratic mobile phase consisted of methanol and water $(85: 15 \mathrm{v} / \mathrm{v})$ at a flow rate of $1.0 \mathrm{~mL} / \mathrm{min}$. BD was detected at $254 \mathrm{~nm}$ with a retention time of $5.9 \mathrm{~min}$. The method was linear $(r=0.9993)$ in the concentration range of $5.0-25.0 \mu \mathrm{g} / \mathrm{mL}$ and precise ( $\mathrm{RSD}<0.96 \%$ for repeatability and $\mathrm{RSD}<1.97 \%$ for intermediate precision).

\section{Nanocapsule suspensions preparation}

The nanocapsules were prepared in triplicate by the interfacial deposition of preformed polymer method (Fessi, Puisieux, Devissaguet, 1988). Two phases were separately prepared: the organic one consisted of acetone, MCT, Span $80^{\circledR}$, PCL and BD, the other was an aqueous dispersion of pullulan. Both phases were kept under magnetic stirring for $60 \mathrm{~min}$. The organic phase was maintained at $40{ }^{\circ} \mathrm{C}$ while the aqueous phase remained at room temperature. In sequence, the organic phase was poured in the aqueous one and the resulting mixture was

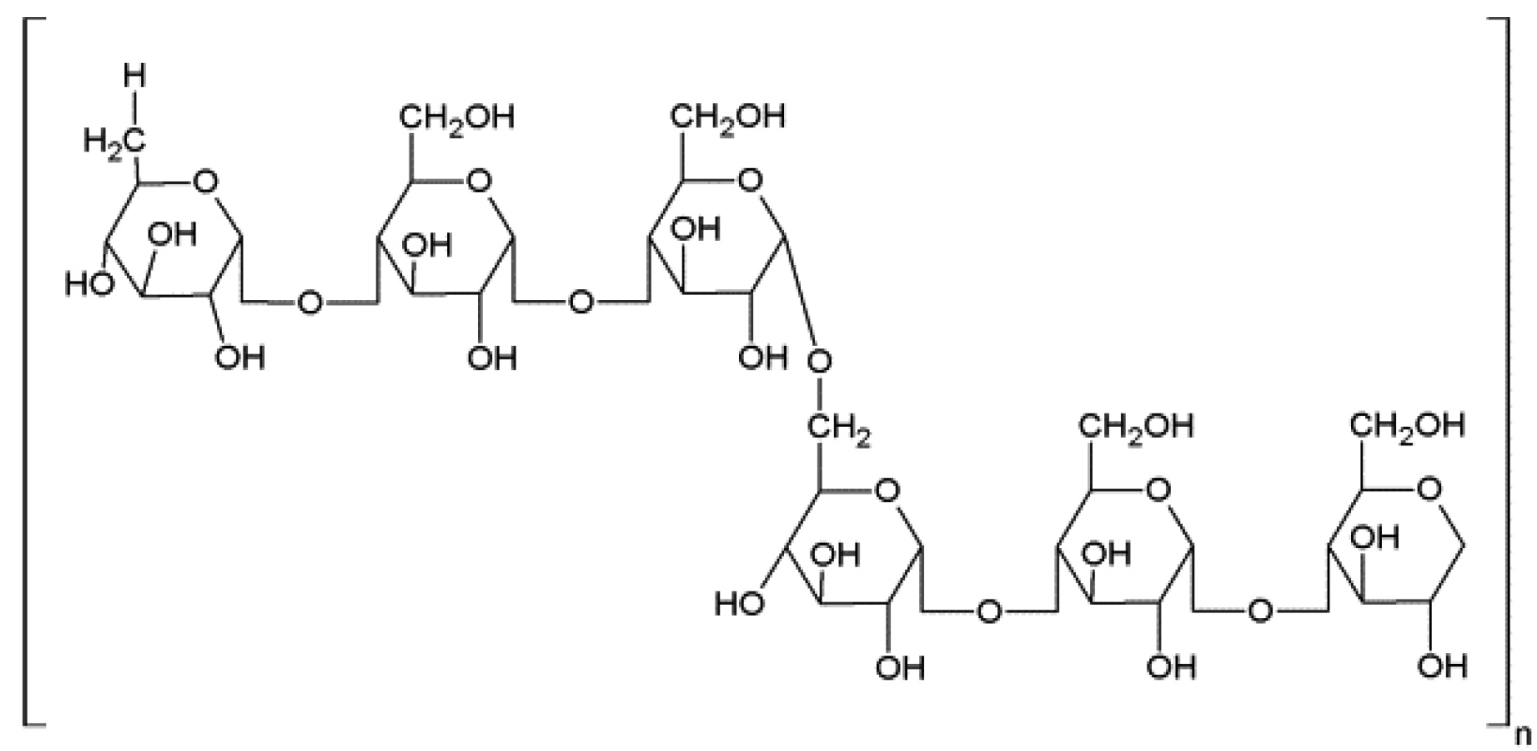

FIGURE 1 - Pullulan chemical structure. 
kept under moderate magnetic stirring for $10 \mathrm{~min}$. Then, the acetone and part of the water were eliminated under reduced pressure to achieve $10 \mathrm{~mL}$ of final volume. For comparison purposes, the formulations were prepared without the drug (blank nanocapsules, NC-B). The quali- and quantitative composition of each formulation is displayed in Table I, and still considering comparative purposes, the nanocapsules were also prepared using polysorbate 80 (NC-0.5-P80 and NC-B-P80).

\section{Nanocapsule suspensions physicochemical characterization}

After preparation, these formulation characteristics were evaluated: $\mathrm{pH}$, particle size, polydispersity index, zeta potential, drug content and encapsulation efficiency. The $\mathrm{pH}$ was directly determined in the samples through a calibrated potentiometer ( $\mathrm{pH} 21$ model, Hanna Instruments). Particle sizes and polydispersity indexes were measured by photon correlation spectroscopy $\left(25^{\circ} \mathrm{C}\right)$ (Zetasizer Nanoseries, Malvern Instruments). Prior analysis, the samples were diluted in ultrapure water (1:500). The Zeta potential was evaluated by electrophoretic mobility (Zetasizer Nanoseries, Malvern Instruments) after the samples dilution (1:500) in $10 \mathrm{mM} \mathrm{NaCl}$ solution. For the BD content determination, an aliquot of nanocapsule suspension was diluted in methanol $(15 \mu \mathrm{g} / \mathrm{mL})$ and the sample was kept $10 \mathrm{~min}$ in an ultrasound, followed by $20 \mathrm{~min}$ of centrifugation at 3,500 rpm. Lastly, the sample was filtered through a regenerated cellulose membrane $(0.45 \mu \mathrm{m})$ and injected into the HPLC system. The encapsulation efficiency was evaluated by the ultrafiltration/centrifugation technique using Amicon ${ }^{\circledR}$ 10,000 MW devices (Millipore). The amount of $200 \mu \mathrm{L}$ of nanocapsule suspension was placed in the device and the centrifugation was carried out at
2,200 $\mathrm{xg}$ for $10 \mathrm{~min}$. The free drug was determined in the ultrafiltrate using the HPLC method described above and the encapsulation efficiency (EE\%) was calculated from the difference between the total and the free drug concentration (Equation 1).

$E E \%=\frac{\text { Total drug content }- \text { Free drug content }}{\text { Total drug content }} \times 100(1)$

\section{Photostability study}

The BD photodegradation incorporated into nanocapsules (NC-0.5) was studied using an UV artificial lamp (Phillips TUV lamp-UVC long life, $30 \mathrm{~W}$ ). For comparison purposes, a BD methanolic solution (BD-MS) and a BD methanolic solution covered with aluminum foil (dark control) were evaluated as well. The samples were placed in plastic cuvettes perfectly stoppered and then exposed to UV radiation in a mirrored chamber $(1 \mathrm{~m} \mathrm{x} 25$ $\mathrm{cm} \times 25 \mathrm{~cm})$, at a fixed distance. After $5 \mathrm{~h}$ of exposure, 300 $\mu \mathrm{L}$ of the samples were withdrawn, diluted in methanol (final BD concentration: $15 \mu \mathrm{g} / \mathrm{mL}$ ), and injected into the HPLC system according to the previously described method. The experiment was performed in triplicate.

\section{In vitro drug release study}

The BD in vitro release from nanocapsules was evaluated by the dialysis bag diffusion technique. The formulation NC-0.5 and a BD ethanolic solution at 0.5 $\mathrm{mg} / \mathrm{mL}$ (BD-ES) were placed in a dialysis bag (MWCO 10,000 , Spectra Por 7) and the system was immersed in $150 \mathrm{~mL}$ of water with $30 \%$ ethanol $\left(37^{\circ} \mathrm{C}, 50 \mathrm{rpm}\right.$ magnetic stirring) to maintain the sink conditions. At predetermined intervals, $1 \mathrm{~mL}$ of the dissolution medium

TABLE I - Quali- and quantitative composition of nanocapsule suspensions

\begin{tabular}{lccccc}
\hline & NC-0.5 & NC-1.0 & NC-B & NC-0.5-P80 & NC-B-P80 \\
\hline Organic phase & & & & & \\
$\quad$ Acetone $(\mathrm{mL})$ & 27 & 27 & 27 & 27 & 27 \\
PCL $(\mathrm{g})$ & 0.1 & 0.1 & 0.1 & 0.1 & 0.1 \\
MCT $(\mu \mathrm{L})$ & 330 & 330 & 330 & 330 & 330 \\
BD $(\mathrm{g})$ & 0.005 & 0.010 & - & 0.005 & - \\
Span $80(\mathrm{~g})$ & 0.077 & 0.077 & 0.077 & 0.077 & 0.077 \\
Aqueous phase & & & & & 53 \\
$\quad$ Water $(\mathrm{mL})$ & 53 & 53 & 53 & 53 & - \\
Pullulan $(\mathrm{g})$ & 0.077 & 0.077 & 0.077 & - & 0.077 \\
$\quad$ Polysorbate $80(\mathrm{~g})$ & - & - & - & 0.077 & \\
\hline
\end{tabular}


was withdrawn and replaced by the same volume of fresh medium. The drug released percentage was determined by the previous mentioned HPLC method. The mean calculated values were obtained from 3 replicates.

Drug release profiles were analyzed by modeldependent approaches: first order equation (Equation 2) and Power law model (Equation 3).

$$
\begin{aligned}
& \frac{M_{t}}{M_{\infty}}=1-\left[e^{-k t}\right] \\
& f t=\frac{M_{t}}{M_{\infty}}=a \cdot t^{n}
\end{aligned}
$$

where $M_{t}$ is the amount of drug released at time $t, M_{\infty}$ is the initial concentration of the drug, $k$ is the kinetic rate constant, $f_{t}$ is the ratio of absolute cumulative amount of drug released at time $t$ and at infinite time, $a$ is a constant incorporating the carrier's structural and geometric characteristics, and $n$ is the release exponent, indicative of the drug release mechanism. The fit of the experimental data to the models was performed using the Scientist 2.0 software (Micromath, USA).

\section{Statistical analysis}

The results were expressed as mean \pm standard deviation. The software used was GraphPad Prism Program, version 5. For the variance analysis (ANOVA) and post-hoc multiple comparisons. The release profiles were analyzed by the two-way ANOVA followed by the post hoc Bonferroni test, while the results of the photostability study were analyzed by the one-way ANOVA, followed by the post hoc Tukey test. In all cases, $\mathrm{p}<0.05$ was considered to be statistically significant.

\section{RESULTS AND DISCUSSION}

Polymeric nanocapsules using pullulan as a stabilizer agent were prepared by the PCL interfacial deposition, a traditional method. Several attempts have been made to optimize the pullulan amount; however, formulations prepared with concentrations lower than $0.6 \%$ precipitated when the evaporation process happened while concentrations upper to $1 \%$ resulted in the formation of precipitates immediately after preparation. In this way, the formulations were prepared with $0.77 \%$ of pullulan, the same concentration generally employed to prepare PCL nanocapsules using polysorbate 80 .

After preparation, regardless of the drug presence, the nanocapsule suspensions showed a milky appearance with an opalescent bluish reflection (Tyndall effect). These characteristics are in accordance to other nanocapsule formulations reported in literature (Mora-Huertas, Fessi, Elaissari, 2010; Schaffazick et al., 2003). In pilot studies, it was observed that there was no formation of nanocapsules without pullulan. Such fact shows the importance of this polysaccharide for the nanocapsule preparation. The Pullulan was essential for interfacial tension reduction allowing the formation of the nanocapsules shell/core structure without precipitation.

Table II displays the physicochemical characteristics of the prepared formulations in comparison to those of nanocapsule suspensions prepared employing polysorbate 80 . The $\mathrm{pH}$ determination revealed that the samples possess values close to the neutrality, which is in accordance to other nanocapsule suspensions prepared with PCL (Ourique et al., 2008; Almeida et al., 2009). As for the particle sizes evaluation, nanocapsules showed an average diameter smaller than $270 \mathrm{~nm}$. Regarding the literature, polymeric nanocapsules usually have dimensions between 100-500 nm (Quintanar-Guerrero et $a l ., 1998)$. Our findings evidenced that the addition of a polymeric emulsifier did not alter the particle sizes when compared to nanocapsules prepared with polysorbate 80 as an emulsifier, and with some reports presented in the literature (Ourique et al., 2008; Fontana et al., 2009). Furthermore, polydispersity indexes were lower than 0.2 indicating a narrow size distribution. Concerning the zeta potential, nanocapsules showed high negative values, that is, higher than formulations prepared with polysorbate 80 (zeta potential $<-12 \mathrm{mV}$ ). As higher the value of the zeta potential was (in modulus), stabler was the nanocapsule suspension due to the repulsive interactions among the particles (Hans, Lowman, 2002). In relation to the drug content, the formulations $\mathrm{NC}-0.5$ and $\mathrm{NC}-1.0$ were close to the theoretical value, with encapsulation efficiencies greater than $99 \%$. It is relevant to mention that in previous trials, PCL nanocapsules prepared with polysorbate 80 were able to incorporate only up to 0.5 $\mathrm{mg} / \mathrm{mL}$ of drug, evidencing that pullulan enhanced the PCL nanocapsules loading capacity. However, the visual monitoring of the formulations prepared with pullulan revealed that $\mathrm{NC}-0.5$ is stabler than the $\mathrm{NC}-1.0$ because this formulation presented precipitates along the storage time. For this reason, studies on the photostability and drug release profiles were performed only for the NC- 0.5 formulation.

In order to evaluate the PCL ability in nanocapsules prepared with pullulan to protect $B D$ against photodegradation, the NC-0.5 samples were exposed to $\mathrm{UVC}$ radiation. After $5 \mathrm{~h}$ of exposure, approximately 
TABLE II - Nanocapsules physicochemical characteristics

\begin{tabular}{lccccc}
\hline Sample & $\begin{array}{c}\text { Actual drug content } \\
(\mathbf{m g} / \mathbf{m L})\end{array}$ & $\mathbf{p H}$ & $\begin{array}{c}\text { Particle size } \\
(\mathbf{n m})\end{array}$ & $\begin{array}{c}\text { Polydispersity } \\
\text { index }\end{array}$ & $\begin{array}{c}\text { Zeta potential } \\
(\mathbf{m V})\end{array}$ \\
\hline NC-B & - & $6.6 \pm 0.2$ & $242 \pm 11$ & $0.18 \pm 0.01$ & $-26.3 \pm 4.6$ \\
NC-0.5 & $0.49 \pm 0.01$ & $6.2 \pm 0.2$ & $270 \pm 2$ & $0.19 \pm 0.02$ & $-22.7 \pm 1.4$ \\
NC-1.0 & $0.99 \pm 0.01$ & $6.7 \pm 0.4$ & $269 \pm 2$ & $0.20 \pm 0.01$ & $-23.1 \pm 0.7$ \\
NC-0.5 P80 & $0.50 \pm 0.02$ & $6.9 \pm 0.3$ & $218 \pm 18$ & $0.14 \pm 0.07$ & $-11.1 \pm 3.4$ \\
NC-B-P80 & - & $6.5 \pm 0.1$ & $291 \pm 65$ & $0.22 \pm 0.03$ & $-12.3 \pm 8.6$ \\
\hline
\end{tabular}

$19 \%$ of the initial BD concentration associated to nanocapsules remained intact (Figure 2). On the other hand, about $5 \%$ of the drug in methanolic solution was maintained under the same experimental conditions. For the dark control, the BD concentration was close to $100 \%$, which discards the influence of chamber temperature on drug degradation.

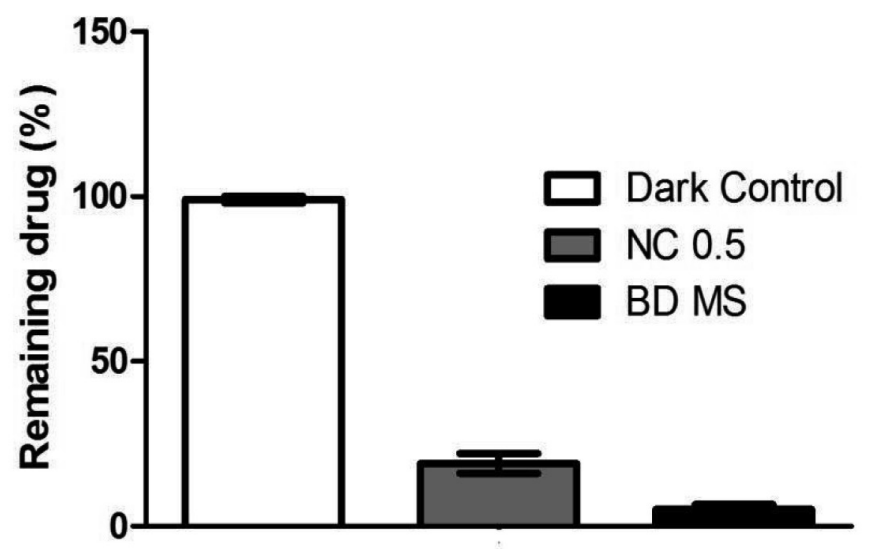

FIGURE 2 - Nanocapsules beclomethasone dipropionate content (NC-0.5), methanolic solution (BD-MS) and dark control under $\mathrm{UVC}$ radiation.

Concerning in vitro drug release experiments, Figure 3 shows that NC-0.5 was able to control BD release in comparison to the ethanolic drug solution. In a 24-hour period, $99.59 \%$ of the free drug was released while $40.48 \%$ of BD was released from nanocapsules in the same period, showing that the nanocarrier prolongs the release.

Mathematical modeling of drug release profiles indicated that both samples followed a first order kinetics $(r>0.99)$, which means that BD release occurred in a single step without a rapid initial release. In relation to the drug release mechanism, the release exponent $n$ obtained from Power law indicates that the BD release from nanocapsules is driven by anomalous transport $(n=0.67)$. According to the literature, systems presenting spherical geometry, $n=0.43$ indicates Fickian diffusion, while $\mathrm{n} \geq 0.85$ is related

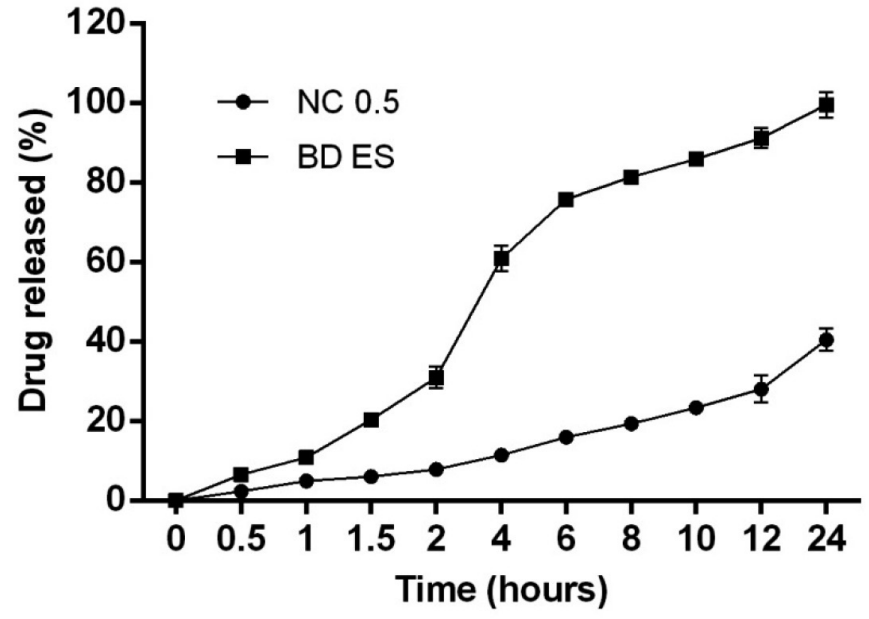

FIGURE 3 - In vitro beclomethasone dipropionate release profiles from nanocapsules (NC-0.5) and ethanolic solution (BD-ES) through the dialysis bag method $(n=3)$.

to case II transport (Peppas, 1985). Values between these limits suggest anomalous transport, i.e., the drug release initially depends on the polymer relaxation followed by Fickian diffusion (Dey et al., 2009).

\section{CONCLUSION}

The use of pullulan as a stabilizer agent for polymeric nanocapsules is reported for the first time. The prepared formulations showed compatible features with other nanostructured systems. The results of zeta potential and drug content indicated that the pullulan is an advantageous stabilizer in comparison to polysorbate 80 . The photostability as well as the in vitro drug release profiles suggest that nanocapsules prepared with pullulan can be considered promising drug carriers.

\section{ACKNOWLEDGEMENTS}

Janaíne Micheli Chassot thanks CAPES/Brazil for the Master's fellowship. 


\section{REFERENCES}

ALLEN, L. D. Remington: the science and practice of pharmacy. 20. ed. London: Pharmaceutical Press, 2004.

ALMEIDA, J.S.; JEZUR, L.; FONTANA, M.C.; PAESE, K.; SILVA, C.B.; POHLMANN, A.R.; GUTERRES, S.S.; BECK, R.C.R. Oil-Based nanoparticles containing alternative vegetable oils (grape seed oil and almond kernel oil): preparation and characterization. Lat. Am. J. Pharm., v.28, p.165-172, 2009.

BOBIN, M.F.; MICHEL, V.; MARTINI, M.C. Study of formulation and stability of emulsions with polymeric emulsifiers. Coll. Surf., A, v.152, p.53-58, 1999.

BROWN, H.M.; GEORGE, G. Beclomethasone dipropionate. A new steroid aerosol for the treatment of allergic asthma. Br. Med. J., v.1, p.585-590, 1972.

CHOUDHARY, D.R.; PATEL, V.A.; CHALOTIYA, U.K.; PATEL, H.V.; KUNDAWALA, A.J. Natural polysaccharides as film former: A feasibility study for development of rapid dissolving films of ondansetron hydrochloride. Int. J. Pharm. Pharm. Sci., v.4, p.78-85, 2012.

DEY, S.K.; MANDAL, B.; BHOWMIK, M.; GHOSH, L.K. Development and in vitro evaluation of letrozole loaded biodegradable nanoparticles for breast cancer therapy. Braz. J. Pharm. Sci., v.45, n.3, p.585-591, 2009.

FESSI, F.; PUISIEUX, F.; DEVISSAGUET, J.P. Procédé de préparation de systèmes

colloïdaux dispersibles d'une substance sous forme de nanocapsules. European Patent No 0274961 A1, 1988.

FONTANA, M.C.; CORADINI, K.; GUTERRES, S.S.; POHLMANN, A.R.; BECK, R.C.R. Nanoencapsulation as a way to control the release and to increase the photostability of clobetasol propionate: influence of the nanostructured system. J. Biomed. Nanotechnol., v. 5, p. 254-263, 2009.

HANS, M.L.; LOWMAN, A.M. Biodegradable nanoparticles for drug delivery and targeting. Curr. Opin. Solid State Mater. Sci., v.6, p.319-327, 2002.

HASSANI, L.N.; HENDRA, F.; BOUCHEMAL, K. Autoassociative amphiphilic

polysaccharides as drug delivery systems. Drug Discov. Today, v.17, p.608-614, 2012.
KAUR, M.; GARG, T.; RATH, G.; GOYAL, A.K. Current nanotechnological strategies for effective delivery of bioactive drug molecules in the treatment of tuberculosis. Cr. Rev. Ther., v.31, n.1, p.49-88, 2014.

KSHIRSAGAR, A.; YENGE, V.; SARKAR, A.; SINGHAL, R. Efficacy of pullulan in emulsification of turmeric oleoresin and its subsequent microencapsulation. In: INTERNATIONAL WORKSHOP ON BIOENCAPSULATION, 15., 2007, Vienna. Proceedings...Vienna, 2007. p.P4-08.

MORA-HUERTAS, C.E.; FESSI, H.; ELAISSARI, A. Polymerbased nanocapsules for drug delivery. Int. J. Pharm., v.385, p.113-142, 2010.

OURIQUE, A.F.; POHLMANN, A.R.; GUTERRES, S.S.; BECK, R.C.R. Tretinoin-loaded nanocapsules: Preparation, physicochemical characterization, and photostability study. Int. J. Pharm., v.352, p.1-4, 2008.

PARK, J.S.; PARK, J-K.; NAM, J-P.; KIM, W-S.; CHOI, C.; KIM, M-Y.; JANG, M-K.; NAH, J-W. Preparation of pullulan- $\gamma$-poly $(L$-lysine $)$ and it's evaluation as a gene carrier. Macromol. Res., v.20, p.667-672, 2012.

PEPPAS, N.A. Analysis of fickian and non-fickian drug release from polymers. Pharm. Acta Helv., v.60, p.110-111, 1985.

PREETZ, C.; RÜBE, A.; REICHE, I.; HAUSE, G.; MÄDER, K. Preparation and characterization of biocompatible oil-loaded polyelectrolyte nanocapsules. Nanomed., v.4, p.106-114, 2008.

QUINTANAR-GUERRERO, D.; ALLÉMANN, E.; FESSI, H.; DOELKER, E. Preparation techniques and mechanisms of formation of biodegradable nanoparticles from preformed polymers. Drug Dev. Ind. Pharm., v.24, p.1113-1128, 1998.

SCHAFFAZICK, S.R.; FREITAS, L.L.; POHLMANN, A.R.; GUTERRES, S.S. Caracterização e estabilidade físicoquímica de sistemas poliméricos nanoparticulados para administração de fármacos. Quim. Nova, v.25, p.726-737, 2003.

SINGH, R.S.; SAINI, G.K.; KENNEDY, J.F. Pullulan: Microbial sources, production and applications. Carbohydr. Polym., v.73, p.515-531, 2008.

Received for publication on $11^{\text {st }}$ December 2014 Accepted for publication on $06^{\text {th }}$ September 2016 